\title{
Mode Research on Space Weapons Systems Innovation Based Quality Function Deployment
}

\author{
Wang Xiuhong \\ Department of Industrial Engineering \\ Zhengzhou Institute of Aeronautical Industry Management \\ Zhengzhou, China \\ wangzzia@zzia.edu.cn
}

\begin{abstract}
-in the aviation industry, experts are enthusiastic over the research of sophisticated weapons. Little specialist pays attention to the innovation modes and methods. Up to now little quantization method suitable for aviation weapon systems innovation is presented. Base on the deep analysis and study on features of aviation weapon systems innovation and different innovation mode from the mass production, we have designed process model and quality chain model of aviation weapon systems innovation. Compared with the process model of large-scale innovation, the process models are more complex including many feedbacks and adding five steps: task decomposition, analysis of knowledge gap, accumulation of key knowledge, outsourcing selection, system integration. Meanwhile manufacturing process and $R \& D$ process are preformed simultaneously, and are involved in the process of module development. Technology application and diffusion are preformed with delivering the final innovation product to user. Quality function deployment and quality house are adopted to deal with the quality transfer among nodes. Quality demands of one node are converted into the technique features of another node in the quality house. We designed the top-down technique features transfer model and bottom-up demands transfer model to solve the quality transfer problems among nodes. At last an example is given to illustrate that this approach can accelerate to blaze the aviation weapon systems trails more than the existing methods and effectively reach quality management of aviation weapon systems innovation.
\end{abstract}

Index Terms-quality chain, aviation weapon systems, quality function deployment, quality house

\section{INTRODUCTION}

Central Military Commission has presented that our national defense should be content with winning local wars under modern, especially high-tech conditions. So our aviation industry must develop the advanced aviation weapon systems suitable for this war. Aviation weapon systems are the particular products based on war demands which have the following features, higher design cost, longer research cycle, higher technology content, more participating manufacturers, more uncontrollable circumstances, more influencing factors and stronger confidential etc. research processes of aviation weapon systems usually are a large system engineering. Each part which generally belongs to field of different technology is also complex system and has close relation with other parts. The whole effect depends on the each part and the relations among the parts. So development of aviation weapon systems is attached to the overall national strength and the whole nation technological level and management level. Counties of the earliest developing aviation weapon systems are the United States and Russia. The United States set up a completely mid-and-long project for developing the systems which can win the competition edge of the future space wars. It plans to form the complete and mature aviation weapon systems up to 2025 including space-based system, foundation systems and components of the above systems. In order to catch the steps of the United States in the aviation weapon systems development, Russia officially established the "celestial army" on June 1, 2001. In view of the NMD systems of the United States, Russia energetically develops the advanced missile systems which can break through the NMP systems.

Up till the present moment, Chinese research on aviation weapon systems is only in its infancy. First, Chinese military technology mainly rely on our own effort because of the kernel technology blockade by Western nations. The other side is lack of innovation theories and innovation methods which determine the ability of concentrating the limited resources to more quickly exploit space weapon systems.

\section{II . THEORIES AND METHODS APPLIED FOR AVIATION WEAPON SYSTEM INNOVATIONS}

In the aviation industry, experts are enthusiastic over the research of sophisticated weapons. Little specialist pays attention to the innovation modes and methods. Modes of large-scale manufacturing and Complex Product \& System (CoPS) innovation are used to develop the current weapon systems.

Mode of large-scale manufacturing is also called massproducing mode. It has the characteristics of producing one or a few similar products which general is standardized products. Production of mass-producing mode is stable and has a high level of specialization. It evolved from America at the end of the 19th century and the beginning of the 20th century. The mode of assembly line has been the primary feature of mass-producing since it was adopted by ford. Other features include interchangeability of components, especial machining tools supporting the interchangeability, standardization of production process, simplification of division of labor, high efficiency, high yield and low cost etc. 
Up to now, theory system suitable for mass-producing mode was established and relatively mature. However, Compared with the mass-producing mode, mode of aviation weapon systems innovation are materially different in product feature, innovation process, production characteristics, market feature etc: many varieties, small batch, limited transaction number, limited competition based on Government control, no size effect, weakening of market and Manufacture effect, direct interaction between core company and supplies, competition focused on systems development and dynamic systems integrate. So theory and methods suitable for mass-producing mode are not qualified for innovation of aviation weapon systems.

In 1996, Hobday found development processes of aircraft engine was distinctly different from that of massproducing products [1]. So he presented the concept of Complex Products \& Systems as distinct from massproducing mode. CoPS are a short form of Complex Products \& Systems. CoPS refer to the large products or infrastructures with high technology content, small mass customization and high integration, for example highspeed train, large communication system, power network control system, large ships, semiconductor production line, information system etc which are in close touch with modern industry. Based on the British various products data, Miller and Hobday who are the SPRU researchers of the Sussex University found value which CoPS created accounted for 11 percent of British GDP and have created at least 1400000-4300000 jobs for British [2]. Hobday stated further that CoPS had played an important role in maintaining the position in the world economy. In 1970, $43 \%$ goods among the most valuable export goods involved the complex technology. In 1996, this ratio can even be as higher as $84 \%$. This indicates that CoPS have played an important role in supporting national economic development. China has melted into global market competition. CoPS development can improve our overall national strength and competitiveness of products.

Aviation weapon systems are typical CoPS. Scholars put forth some modes and methods based on the actual CoPS cases. But scholars have arguedd endlessly the fact that these are suitable for all CoPS or not. There has been not a manure theory system of CoPS innovation up to the present. Taking cellular communication system as an Example, Andrew Davies analyzed the characteristics and key problems in each period of the life cycle [3]. He thought relevant government departments should play an important role in the CoPS innovation, especially in policies and development fund supporting. Huaglory and Tianfield presented a new Life Cycle Model which was named circle Life Cycle Model [4]. Many existing modes, such as concurrent engineering, life cycle engineering, virtual prototype, software engineering etc, are involved in the above model. But Chen Jin professor thought CoPS development have not evident feature of the life cycle [5]. Qi Ershi professor proposed virtual organization is a valid mode suitable for CoPS development [6]. However Through a great many empirical research Massimo and Andrea found as a management mode virtual organization has been generally used in the industries [7]. Aviation weapon systems are taken as an example to show virtual organization is unsuitable for CoPS innovation. Hardstone G.A.P compared the structures, functions, and strategy of companies which did not develop the CoPS with those of companies which began to study the CoPS[8]. He reexamined enterprise competence theory, competitiveness theory and industry overall planning theory. He thought PBO (organization form based on project) were ideal organization forms for CoPS innovation. And Garm and Ammon J.Salter aimed at the processes and methods of project management in the CoPS innovation such as organization form based on project, knowledge management based on project and team management based in project etc. However based on the detailed comparison between PBO and organization form of traditional function matrix, Mike Hobday thought PBO were not perfect organization form for CoPS innovation[9]. PBO is valid in handling some problems, such as risk, uncertainty attached to customer needs and knowledge reorganization etc. But PBO had some defects in dealing with routine work, benefiting from economies of scale, obtaining cross-project resources, utilizing allwave technical support from the company, and performing the wide organizational learning. He had an opinion that CoPS developments need many organization forms. The properties, scale and structure of products are the principal consideration for the selection of organization forms.

In light of the above studies, it is a key problem and pressing task that suitable innovation mode was designed to accelerate to blaze the aviation weapon systems trails throughout the aviation industry. Complexity of aviation weapon systems innovation roots in a great quantity of subsystems, absolute diversity of subsystems and relation multiplicity among subsystems. It is indeed multi-body systems in which many techniques affecting one another are used in the different layer subsystems and innovation modes of CoPS must integrate process with system. The true cause of these controversies lies in the fact that though modified according to some features of CoPS, existing innovation modes of CoPS are still based the innovation modes of large-scale products. These modes of aviation weapon systems innovation are not drastically regenerated according to the tremendous difference between aviation weapon systems and large-scale products. Especially innovation stages are still classified by life cycle theories and takes "product circuit" as the main line. For example, the following are two typical process modes of CoPS innovation. Brady and Davies [10] divided the process of CoPS innovation into six stages by the value chain: an early stage, manufacturing, systems integration, transportation, services provision and the process of final consumption. In light of the special properties of CoPS, Chen Jin [6] proposed a six-stage model: Innovative ideas, task decomposition, outsourcing options, module development, systems integration and delivery \& improve.

Products quality is the key factor of aviation weapon systems innovation success or no. Almost all failing cases 
are relevant to the imperfect quality control. Compared with quality control of large-scale products which pays attention to the production quality, quality control of aviation weapon systems is focus on design quality, system integration quality, service quality and supplier quality etc. Quality control runs through entire innovation course of aviation weapon systems and forms a quality chain. In the other word, development of aviation weapon systems is also the process of quality chain forming from product conception of fine quality, product design, product production, product integration, to product supply of fine quality. So it is very suitable that quality is seemed as the fundamental issue of concern to design the innovation mode for aviation weapon systems. Quality chain management is the high efficiency method: it takes the quality process achieved together by various organizations and various elements as background, and take quality and information and value flows as research object. By means of fixing the key nodes of quality chain, coordination model and coupled model of nodes are performed to control the key nodes.

In this paper, quality chain is used to design the mode of aviation weapons systems innovation. We performed the network model of quality chain. Nodes which are consist of the suppliers and manufacturers and customers etc and lines among nodes which are process of quality transmission are involved in the network. We adopt quality function deployment (QFD) and quality house to handle the process of quality transfer among the nodes. This approach can improve the quality level of aviation weapon systems innovation as well as effectively cutting into innovation cost.

\section{FEATURE OF AVIATION WEAPON SYSTEMS INNOVATION}

Development of aviation weapon systems is based on the large-scale product innovation but have sensible difference.

\section{A Systematization and Complexity}

It is difficult to forecast the result of aviation weapon systems innovation because its processes are nonlinear with time change. A micro-variation of sub-systems between generations can bring about massive changes in overall function of the entire system. Complexity of aviation weapon systems innovation comes through in the following three parties: First, aviation weapon systems included so much integral structure and component parts which are classified as the different sub-systems according to their function. Many sub-systems contain some inner software systems, so only in the customized way can they satisfy the whole systems function. Second, the relations among elements in every sub-system, among every sub-system in the whole systems, and between each sub-systems and the whole system are very complex. The relations are nonlinear and dynamic with time change. At last, research on aviation weapon systems has covered several domains and techniques such as computer, electron, machinery, even chemistry and physics etc.

\section{$B$ Strengthened Function of System Design and Integration}

Aviation weapon systems are mostly customized products. Small batch based on project form is their production mode. Its features appear in limited number of transactions and controlled competition by government. Systems design and integration are the key processes of aviation weapon systems innovation. There are not individual processes of manufacturing and expanded reproduction and market expansion which are most important processes of large-scale production. Innovation has shaped when the whole $R \& D$ process finished. These processes have melted into $R \& D$ process. In most cases, development is to meet customer demands. So it is classic customized product which need not market expansion. Only after innovation is finished and a series of technical improvements is made, there are the distinct processes of market expansion.

\section{Communication and Iinteraction throughout the Entire Process}

In the large-scale production, demands are transferred though the information of market transaction. But in the development of aviation weapon systems, Core Company has a fairly close communication and interaction with customers and important supplies in the whole innovation process. Customer directly participate the whole process. Even are sometimes face-to-face. Some systems including software development must be improved continuously according to the customers' demands. Furthermore, suppliers are not merely the companies which supply the core company with raw materials and mechanical equipments. They are pestered to join in the some processes of aviation weapon systems innovation. And even the key suppliers must participate in the whole processes.

\section{QUALITY CHAIN MODEL OF AVIATION WEAPON SYSTEMS INNOVATION}

Quality control processes of aviation weapon systems innovation are based on the process of their innovation. Development of aviation weapon systems begins with innovation task issued by military or government which is also the end user (customer). When innovation first occurred, user' demands generally are vague and are difficult to portray by technical terms because user is not very familiar with the aviation weapon systems. User only can put forward the requirement from the function. Systems design was finally completed and converted to requirement definition under communication and interaction between Core Company and user. R\&D process goes on in parallel with manufacturing process. It usually is recursive processes of R\&D-manufacturingmodification-R\&D. researches are finished at the same time manufacturing processes are completed. There are not significant and independent manufacturing processes. So in the stage, quality of information transmission between Core Company and user is key factor of influencing the success of aviation weapon systems innovation or no. Core Company often is confronted with 
knowledge gaps because technical composition of aviation weapon systems is very complex and covers a lot of subjects and most companies hold the limited knowledge. Knowledge gaps are differences between existing knowledge and requiring knowledge for realizing its strategic goals. In light of difficult or easy degree, requiring knowledge can be divided into basic knowledge, forward knowledge, technical knowledge and assistant knowledge. Basic knowledge is the manure basic theory and knowledge of each subject as physics and chemistry. Forward knowledge is the latest research results of relative subjects such as new Materials. Technical knowledge is close relation with product and production technique. Assistant knowledge is other knowledge which provides a service for the above knowledge such as policies and rules, management methods etc. meanwhile, quality of basic knowledge embodies the national innovation capability. Gaps of basic knowledge can not be made up in a short time. It is from knowledge gaps that all innovation failures of aviation weapon systems spring. So quality of knowledge development and knowledge transfer are key factors in the stage.

According to the above analysis, we design the process model of aviation weapon systems innovation shown in the Fig 1. Compared with the process model of large-scale innovation, the process models is more complex including many feedbacks and adding five steps: task decomposition, analysis of knowledge gaps, accumulation of key knowledge, outsourcing selection, system integration. Meanwhile manufacturing process and $R \& D$ process are preformed simultaneously, and are involved in the process of module development. Technology application and diffusion are preformed with delivering the final innovation product to user.

Based on the process model, we set up the quality chain model of aviation weapon systems innovation. It is a network model and is three dimensions structure. Lateral dimension expresses the quality management in nodes settings which is based on the supply chain of aviation weapon systems innovation. Longitudinal dimension is the inner quality management including quality policy, quality planning, quality management level and quality improvements etc. The last expresses the relations among the nodes. The nodes refer to the external cell of the Core Company related with innovation such as suppliers, customers and research institute etc. quality chain model of is shown in the following Fig 2.

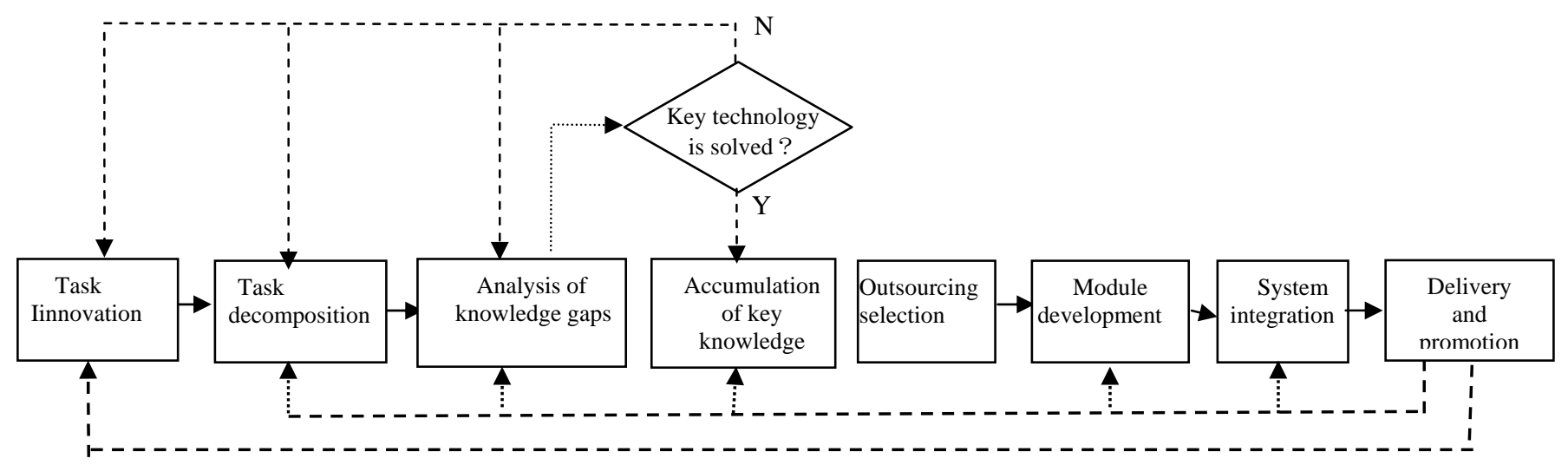

Figure 1. Process model of aviation weapon systems innovation

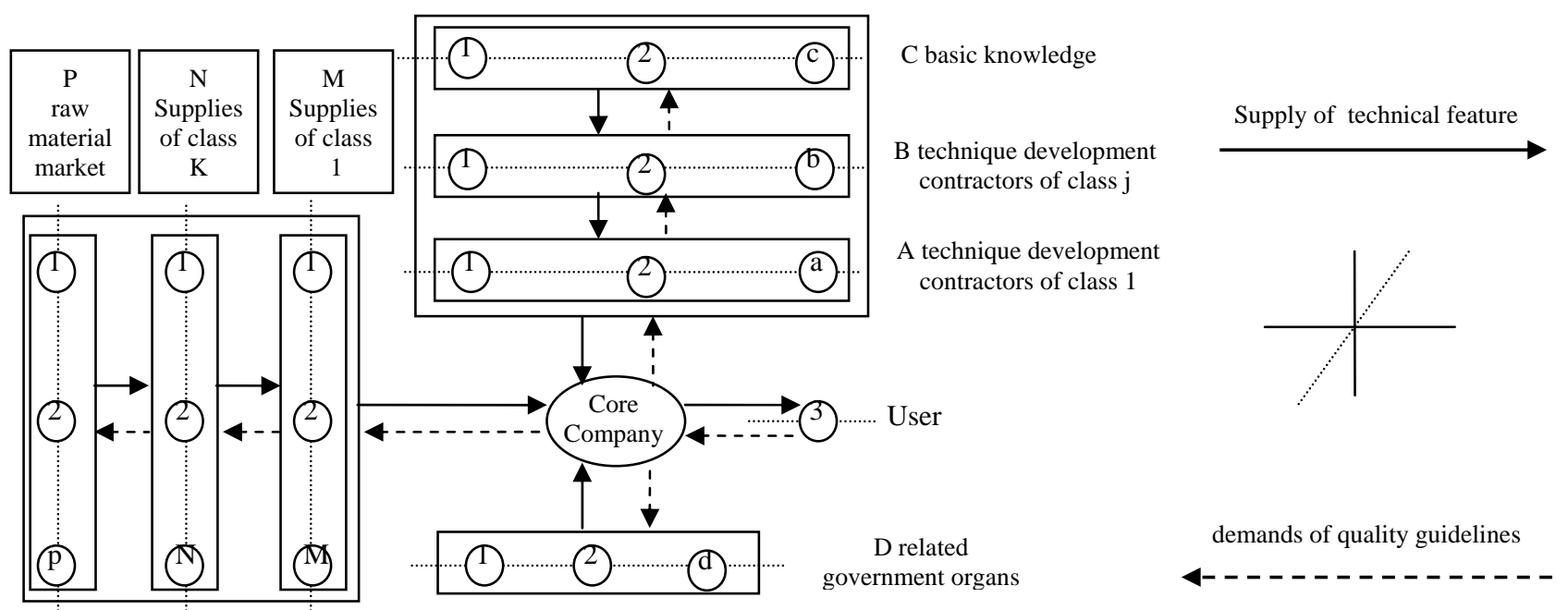

Figure 2. Quality chain model of aviation weapon systems innovation 
Lines among nodes express the quality transfer procession. Quality is a set of features which must satisfy the users' demands. Quality demands of upstream companies on downstream companies appear in a set of the quantity quality guidelines. These guidelines deliver from downstream companies to upstream companies in accordance with the dash line direction. At the same time, upstream companies deliver information on product technology to downstream companies and attend product design in accordance with the solid line direction.

The above quality transfer procession is very complex. Some problems need be solved such as consensus problem among nodes, coupling problems in the quality transfer procession, information distortion etc. Up to now, no scholar studies the quality problems of aviation weapon systems innovation. A few scholars presented some methods, which are suitable to the large-scale products innovation, to study the quality delivery between nodes. R.B.XIAO adopted the advanced SCOR to set up a process model of closed loop quality chain. M.Y.SHAN used customizable DEA model to solve the consensus problem of among nodes. In the paper, we adopt advanced quality function deployment and quality house to deal with the quality relation between nodes.

\section{QUALITY CHAIN MODEL BASE ON QFD METHOD}

Connotation of QFD is to listen to and care for the customers' demand in product design. So first is to know consumers' demands for products, and then transfer the consumers' demands into quality features of products (technology parameter). QFD is an integrated technique which involves customer requirement review, value engineering, fuzzy clustering analysis, topological linear space, analytic hierarchy process etc. Quality house is its key part.

In the quality chain of aviation weapon systems innovation, customers' demands must be converted into product technical feature and finally be converted into the quality demands to all nodes through demand transmission from downstream companies to upstream companies. All nodes are linked by quality house in which quality demands of each node from $\mathrm{P}$ raw material market to $\mathrm{N}$ supplies of class $\mathrm{k}$, then to $\mathrm{M}$ supplies of class 1 , finally to Core Company, and from $\mathrm{C}$ basic knowledge to $\mathrm{B}$ technique development contractors of class $\mathrm{j}$, then to A technique development contractors of class 1 , finally to Core Company, and from D related government organs to Core Company, and from Core Company to user. Quality transfer model is shown in Fig 3. The model of quality house is shown as the following Fig 4.

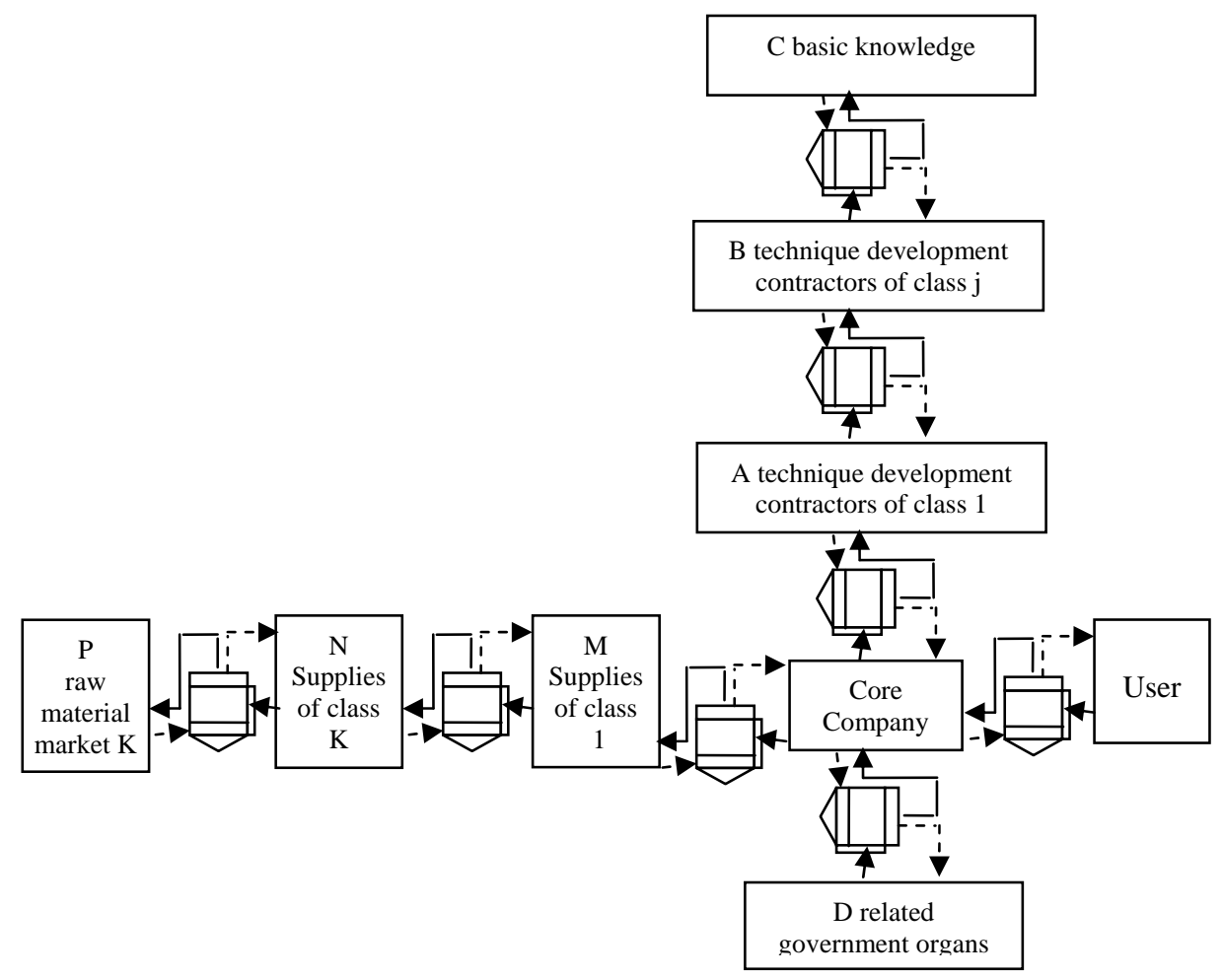

Figure 3. Quality transfer model of in the quality chain model of aviation weapon systems innovation 

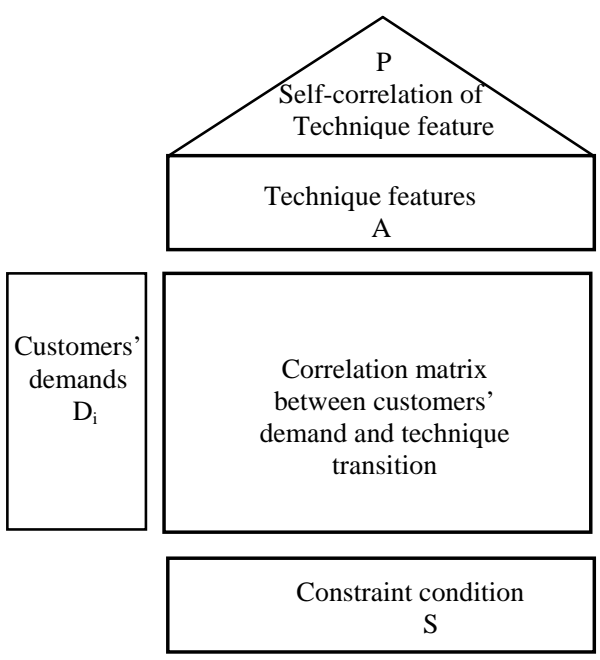

Figure 4. the model of quality house

Let $\mathrm{i}=1,2, \ldots, \mathrm{k}$ stand for $\mathrm{K}$ nodes where i represents random node. And $\mathrm{j}=1, \ldots, \mathrm{q}$ expresses the number of incomes and outcomes of the nodes. Nodes except Core Company only have an income and an outcome from the Fig 3.

\section{A Particular Meaning of Symbols in the Quality House}

Columns matrix $\mathrm{D}_{\mathrm{i}}$ stands for the customers' demands or demands of downstream companies to upstream companies. It usually is a series of guidelines from the customers' investigation. Columns matrix $\mathrm{W}_{\mathrm{i}}$ stands for the weight of demands guidelines. Row Matrix $A_{i}$ represents the product technique features. Matrix $P_{i}$ represents the correlation among product technique features.

Matrix $\mathrm{R}_{\mathrm{i}}$ expresses the correlation between customers' demands and product technique features. Numbers in matrix $R_{i}$ equal to 0 , positive quantity and negative quantity indicate irrelevant, positive correlation and conflicting interrelationships between customers' demands and product technique features. Matrix $P_{i}$ stands for the self-correlations of technique features. We have:

$$
D_{i} R_{i} P_{i} \stackrel{s_{i}}{\rightarrow} A_{i}
$$

Where $S_{\mathrm{i}}$ is a transfer matrix and its function is to build the relation between technique features of upstream companies and customers' demands of downstream companies. That is to say,

$$
D_{i+1}=A_{i 1} S_{i 1} \oplus A_{i 2} S_{i 2} \oplus \ldots \oplus A_{i q} A_{i q}
$$

Where $\oplus$ is a symbol which expresses the integration of nodes incomes or outcomes.

\section{B Demands Transfer Model}

If customers' demands of downstream companies produce fluctuation, this fluctuation will be transmitted to the upstream companies and cause fluctuation of technique features of upstream companies. Bottom-up demands transfer model is designed and shown in the following formula (3) according for (1) and (2).

$$
\text { . }\left\{\begin{array}{l}
A_{0}=D_{0} R_{0} P_{0} \\
A_{i+1}=A_{i 1} S_{i 1} R_{i+1,1} P_{i+1,1} \oplus A_{i 2} S_{i 2} R_{i+1,2} P_{i+1,2} \oplus \ldots \oplus A_{i q} S_{i q} R_{i+1, q} P_{i+1, q}
\end{array}\right.
$$

\section{Technique Feature Transfer Model}

Similarly, when technique features of upstream companies appear disturbances, the disturbance can also be transferred to the downstream companies and bring forth the disturbances of customers' demands. We can also obtain the top-down technique feature transfer model.

$$
\left\{\begin{array}{l}
D_{k}=A_{k}\left(P_{k}\right)^{T}\left(R_{k}\right)^{T} \\
D_{1-1}=D_{11}\left(S_{i 1}\right)^{T}\left(P_{i-1,1}\right)^{T}\left(R_{i-11}\right)^{T} \oplus D_{12}\left(S_{i 2}\right)^{T}\left(P_{i-1,2}\right)^{T}\left(R_{-1,2}\right)^{T} \oplus \ldots \oplus D_{1 q}\left(S_{i q}\right)^{T}\left(P_{i-1, q}\right)^{T}\left(R_{i-1, q}\right)^{T}
\end{array}\right.
$$

\section{MODEL AND QUALITY ANALYSIS OF AVIATION WEAPON SYSTEMS INNOVATION}

Taking an innovation of aircraft engine as an illustration, we use the above model to analyze the quality control process. For simplicity and expressing the above model clearly, we only consider the quality transfer between two nodes in quality chain. In other words, we suppose that quality chain of aircraft engine innovation only involves two nodes that are a supplier and Core Company. The supplier makes camshaft of engine and Core Company assembles the engine.

We select the indexes: validity, reliability, economy, flexibility, confidentiality to stand for customers' demands of Core Company and the guidelines: weight, engine power, accuracy express the technique features of Core Company. Value of the above guidelines are all indicated in integer between 0 and 10 which are used to substitute for practical significance of technical parameters. all parameters values of costumers' demands and technique features of Core Company are shown in table $\mathrm{I}$ and $\Pi$.

TABLE I.

AUTOCORRCLATION MATRIX P1 OF TECHNIQUE FEATURES OF CORE COMPANY

\begin{tabular}{|l|l|l|l|}
\hline & weight & engine power & accuracy \\
\hline weight & 1 & 0.476 & -0.347 \\
\hline engine power & 0.476 & 1 & 0.758 \\
\hline accuracy & -0.347 & 0.758 & 1 \\
\hline
\end{tabular}

TABLE II.

RELATION MATRIX R1 OF CORE COMPANY BETWEEN CUSTEMORS' DEMANDS AND TECHNIQUE FEATURES

\begin{tabular}{|l|l|l|l|}
\hline & weight & engine power & accuracy \\
\hline validity & 0.864 & 0.889 & 0.261 \\
\hline reliability & 0.272 & -0.214 & 0.114 \\
\hline economy & -0.390 & -0.547 & -0.270 \\
\hline flexibility & -0.543 & -0.126 & -0.336 \\
\hline confidentiality & -0.265 & 0.653 & 0.381 \\
\hline
\end{tabular}

We adopt the guidelines: material characterization and manufacturing technology to stand for technique features of supplier and select the indexes: weight, torsion, 
hardness to represent costumers' demands of supplier. And for the same reason, Value of the above guidelines are all indicated in integer between 0 and 10 which are used to substitute for practical significance of technical parameters. Values of parameters are shown in table III and IV.

TABLE III.

AUTOCORRCLATION MATRIX P2 OF TECHNIQUE FEATURES OF SUPPLIER

\begin{tabular}{|l|l|l|}
\hline & material characterization & manufacturing technology \\
\hline $\begin{array}{l}\text { material } \\
\text { characterization }\end{array}$ & 1 & 0 \\
\hline $\begin{array}{l}\text { manufacturing } \\
\text { technology }\end{array}$ & 0 & 1 \\
\hline
\end{tabular}

TABLE IV.

RELATION MATRIX $\mathrm{R}_{2}$ OF SUPPLIER BETWEEN CUSTEMORS’ DEMANDS AND TECHNIQUE FEATURES

\begin{tabular}{|l|l|l|}
\hline & material characterization & manufacturing technology \\
\hline weight & 1 & 0 \\
\hline torsion & 1 & 1 \\
\hline hardness & 0 & 1 \\
\hline
\end{tabular}

Matrix S of conversion ratio between customers' demands of upstream company and technique features of downstream company is shown in the following table $\mathrm{V}$.

TABLE V.

MATRIX $\mathrm{S}_{2}$ OF CONVERSION RATIO

\begin{tabular}{|l|l|l|l|}
\hline & weight & torsion & hardness \\
\hline weight & 0.326 & & \\
\hline engine power & & 0.745 & \\
\hline accuracy & & & 1 \\
\hline
\end{tabular}

In table $\mathrm{V}$, data 0.326 expresses that request weigh of camshaft can not be more than $32.6 \%$ of the whole engine weight and torsion rate not more than $74.5 \%$ of engine power. Data 1 stands for that demand of accuracy is upward delivered completely.

\section{A Quality Chain Analysis for Customers' Demands Fluctuation}

Because of uncertainty of customers' demands and fuzziness of customers' description to aviation weapon systems function, Customers often change demands according to their growing understanding for aviation weapon systems innovation. Sometimes a subtle change can cause the massive changes of the whole system. So it is a key task to analyze quality fluctuation of nodes and provide the solution to these problems. If customers' demands change, we use number 0 or 1 to express the variation of customers' demands. Number 0 represents the indexes not to be changed. On the contrary, Number 1 represents the indexes to be changed. We assume the variation of customers' demands $\mathrm{D}_{1}$ of Core Company from $D_{1}=(0,0,0,0,0)$ to $D_{1}=(1,0,1,0,1)$. Then in light of formula (3), variation of technique features of supplier is calculatedd and shown in the following.

$$
\begin{aligned}
& A_{1}=D_{1} R_{1} P_{1}=\left[\begin{array}{lllll}
1 & 0 & 1 & 0 & 1
\end{array}\right] \\
& \begin{array}{l}
{\left[\begin{array}{ccc}
0.864 & 0.889 & 0.261 \\
0.272 & -0.214 & 0.114 \\
-0.390 & -0.547 & -0.270 \\
0.543 & -0.126 & -0.336 \\
0.265 & 0.653 & 0.381
\end{array}\right]\left[\begin{array}{ccc}
1 & 0.476 & -0.347 \\
0.476 & 1 & 0.758 \\
-0.347 & 0.758 & 1
\end{array}\right]} \\
=\left[\begin{array}{lll}
0.739 & 0.995 & 0.372
\end{array}\right]\left[\begin{array}{ccc}
1 & 0.476 & -0.347 \\
0.476 & 1 & 0.758 \\
-0.347 & 0.758 & 1
\end{array}\right]
\end{array} \\
& =\left[\begin{array}{lll}
1.084 & 1.629 & 0.870
\end{array}\right] \\
& A_{2}=A_{1} S_{2} R_{2} P_{2}=\left[\begin{array}{lll}
1.084 & 1.629 & 0.870
\end{array}\right] \\
& \begin{array}{l}
{\left[\begin{array}{ccc}
0.326 & 0 & 0 \\
0 & 0.745 & 0 \\
0 & 0 & 1
\end{array}\right]\left[\begin{array}{ll}
1 & 0 \\
1 & 1 \\
0 & 1
\end{array}\right]\left[\begin{array}{ll}
1 & 0 \\
0 & 1
\end{array}\right]}
\end{array}
\end{aligned}
$$

According to the above results, when variation of customers' demands $\mathrm{D}_{1}$ of Core Company is from $\mathrm{D}_{1}=(0,0,0,0,0)$ to $\mathrm{D}_{1}=(1,0,1,0,1)$, technique features of Core Company also change with weight improving 1.084 units, engine power increasing 1.629 units and accuracy improving 0.870 units. At the same time, through the quality transfer from Core Company to supplier, technique features are also change with material characterization improving 1.214 units and manufacturing technology improving 2.084 units.

\section{B Quality Chain Analysis for Fluctuation of Supplier's Technique Features}

In real production, company production conditions often change with technical improvement and management innovation and worker skill improving. Furthermore, performances of raw materials is not constant and there exists a spontaneous variation. These directly influence product function and customer satisfaction. We suppose the variation of supplier's technique features $A_{2}$ equal $A_{2}=(1,-1)$. Then according for the formula (4), variation of customers' demands of Core Company is calculatedd and shown in the following.

$$
\begin{gathered}
D_{2}=A_{2}\left(P_{2}\right)^{T}\left(R_{2}\right)^{T}=\left[\begin{array}{ll}
1 & -1
\end{array}\right] \\
{\left[\begin{array}{ll}
1 & 0 \\
0 & 1
\end{array}\right]\left[\begin{array}{lll}
1 & 1 & 0 \\
0 & 1 & 1
\end{array}\right]=\left[\begin{array}{lll}
1 & 0 & -1
\end{array}\right]} \\
D_{1}=D_{2}\left(S_{2}\right)^{T}\left(P_{1}\right)^{T}\left(R_{1}\right)^{T}=\left[\begin{array}{lll}
1 & 0 & -1
\end{array}\right] \\
{\left[\begin{array}{ccc}
0.326 & 0 & 0 \\
0 & 0.745 & 0 \\
0 & 0 & 1
\end{array}\right]\left[\begin{array}{ccc}
1 & 0.476 & -0.347 \\
0.476 & 1 & 0.758 \\
-0.347 & 0.758 & 1
\end{array}\right]} \\
{\left[\begin{array}{ccccc}
0.864 & 0.272 & -0.390 & 0.543 & 0.265 \\
0.889 & -0.214 & -0.547 & -0.126 & 0.653 \\
0.261 & 0.114 & -0.270 & -0.336 & 0.381
\end{array}\right]} \\
=\left[\begin{array}{lcccc}
-0.245 & 0.185 & 0.368 & 0.796 & -0.649
\end{array}\right]
\end{gathered}
$$

The above result indicate that variation of supplier's technique features has much effect on customers' demands. If technique features changes of supplier with material characterization increasing 1 unit and manufacturing technology reducing 1 unit at the same time, all costumers' demand guidelines generate changes with validity and confidentiality reducing 0.245 units and 0.649 units separately. At the same time, reliability, economy, flexibility improve 0.185 units, 0.368 units and 0.796 units separately. 


\section{CONCLUSION}

Base on the deep analysis and study on features of aviation weapon systems innovation, we have designed process model and quality chain model of aviation weapon systems innovation. Despite that some scholars have a profound interest in quality problem of aviation weapon systems innovation, up to now little suitable and quantization method is presented. In the paper we adopt quality house to deal with the relation among nodes of quality chain and build the quality transfer model of aviation weapon systems innovation. The model shows clearly the process of quality transfer from downstream company to upstream company when customer's demands produce disturbance and from upstream company to downstream company when technique features produces disturbance. The above study can solve the quality control problem of aviation weapon systems innovation effectively.

\section{ACKNOWLEDGMENT}

This paper was supported by the grants from National Natural Science Foundation of China (No 70771102), Aeronautical Science Foundation of China (No ZG55025) and Science Foundation of he nan province (No 092400430069).

\section{REFERENCES}

[1] Mike Hobday, The project-based organization: an ideal form for managing complex products and systems, Research Policy, 2000, 29 (7) : 871-893

[2] Roger Miller and Mike Hobday, "Innovation in Complex Systems Industries: the Case of Flight Simulation” [J]. Industrial and Corporate Change. vol 4(2). pp 362400.1995

[3] Andrew Davies, the Life Cycle of a Complex Product System, International Journal of Innovation Management, 1997, 1 (3) : 229-256

[4] Huaglory and Tianfield. "Advanced life-cycle model for complex product development via stage-aligned information-substitutive concurrency and detour" [J]. International Journal of Computer Integrated Manufacturing.vol 14 (3) .pp 281-303.2001

[5] Chen Jin and Zhou Zifan, A mode of complex products and system innovation, China Academic Journal,2005(2): 61-67

[6] Huo Yanfang and Qi Ershi, Study on the integrated Development Model of Complex Product Systems Based Virtual Organizations, Manufacturing Technology \& Machine Tool, 2004(9):46-49

[7] Massimo Paoli \& Andrea Prencipe, The Role of Knowledge Bases in Complex Product Systems: Some Empirical Evidence from the Aero Engine Industry, Journal of Management and Governance, 1999 , 3 (2) : 117-201

[8] Hardstone G.A.P, Capabilities, Structures and Strategies Re-Examined: Incumbent Firms and the Emergence of Complex Product Systems(CoPS)in Mature Industries, Technology Analysis and Strategic Management, 2004, 16 (2) : 173-196
[9] Roger Miller \& Mike Hobday, Innovation in Complex Systems Industries: the Case of Flight Simulation [J], Industrial and Corporate Change, 1995, 4 (2) : 362400

[10] [10] Brady.T, Tools, Management of Innovation and Complex Product Systems, Working Paper Prepared for CENTRIM/SPRU Project on Complex Product Systems/EPSRC, Technology Management Initiative, 1995

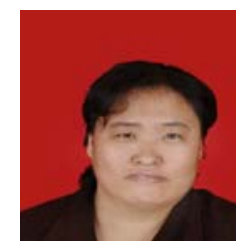

Wang Xiuhong was born in Chen De of he bei province on April ,twenty-ninth 1974. She received her Bachelor and Master from Hua zhong Agriculture University.

He's been working in the Zhengzhou Institute of Aeronautical Industry Management since leaving school. Now she is an associate professor and head of the department of industry engineering. She takes an interest in the studies of knowledge management, quality engineering and industry engineering and with 4 works and more than 30 academic theses being published. 